\title{
VINTE ANOS DE HOMICÍDIOS NO ESTADO DE SÃO PAULO
}

Paulo Borlina Maia

Historiador, Analista da Fundação Seade

$\mathrm{A}$ s mortes violentas no Brasil ao longo destas últimas décadas vêm assumindo proporções cada vez maiores, o que tem gerado um intenso debate nos mais variados setores da sociedade. Embora não seja um fenômeno exclusivo da sociedade brasileira, uma vez que ela atinge vários países com diferentes níveis de desenvolvimento, variando apenas de intensidade e padrão, muitos estudos têm se dedicado a este problema. Em geral, consideram mais especificamente a questão da violência urbana, cuja expressão maior pode ser observada em suas regiões metropolitanas (Camargo et alli, 1995). Indicam que as principais vítimas por homicídios são jovens do sexo masculino, de cor parda ou negra, com baixa escolaridade e pouca qualificação profissional (Mello Jorge, 1988; Szwarcwald, 1989; Souza e Assis, 1989; Souza, 1994; Minayo, 1994; Saad et alli 1998). Segundo Ferreira e Castiñeira (1996), esse fenômeno vem provocando uma regressão no padrão de mortalidade da população paulista. De acordo com estes autores, a importância que estas mortes vêm assumindo, particularmente entre a população masculina de 15 a 34 anos de idade, pode, em um futuro próximo, acarretar uma estagnação e até mesmo reversão nos ganhos da esperança de vida ao nascer.

Neste sentido, as estatísticas vitais produzidas pela Fundação Seade, que contam atualmente com uma série histórica de mais de um século de existência, permitem analisar a dinâmica demográfica do Estado de São Paulo para diversas desagregações regionais, mostrando as principais alterações ocorridas com relação aos nascimentos, casamentos e óbitos.
Desta forma, é possível avaliar a evolução temporal da mortalidade por homicídios e sua distribuição no território paulista. O detalhamento das informações existentes, tais como sexo, idade, tipo de morte, entre outras, constitui um instrumento de monitoramento da mortalidade, contribuindo para o planejamento de ações na área de segurança, no sentido de minimizar esta questão, que assume importância cada vez maior em vários setores da sociedade.

Assim, o objetivo deste trabalho é apresentar a evolução da mortalidade por homicídios no Estado de São Paulo nas duas últimas décadas do século XX, considerando os diferenciais segundo alguns atributos. Pretende-se também avaliar a distribuição espacial destes homicídios no Estado, bem como explorar outras variáveis contidas no banco de dados de óbitos, que é produzido na Fundação Seade a partir das declarações de óbitos coletadas nos Cartórios de Registro Civil de todos os municípios paulistas.

\section{HOMICÍDIOS DO ESTADO NO CONTEXTO NACIONAL E INTERNACIONAL}

A Tabela 1 apresenta as taxas de mortalidade por homicídios segundo sexo para alguns países selecionados e para o Estado de São Paulo. Apesar da defasagem no tempo, e de as áreas analisadas se referirem apenas a países, a comparação permite avaliar a real dimensão da mortalidade por homicídios no Estado.

Uma característica comum a todos os países analisados é que os índices de mortalidade por homicídios na 
TABELA 1

Taxas de Mortalidade por Homicídios, por Sexo Países Selecionados e Estado de São Paulo - 1991-1997

\begin{tabular}{lccr} 
& \multicolumn{2}{c}{ Por 100 mil habitantes } \\
\hline $\begin{array}{l}\text { Países e } \\
\text { Estado de São Paulo }\end{array}$ & $\begin{array}{c}\text { Ano da } \\
\text { Informação }\end{array}$ & Homens & Mulheres \\
\hline Colômbia & 1991 & 167,60 & 12,60 \\
Estado de São Paulo & 1993 & 50,25 & 4,06 \\
Rússia & 1993 & 49,50 & 13,50 \\
Brasil & 1997 & 46,86 & 4,43 \\
México & 1992 & 33,93 & 3,70 \\
EUA & 1991 & 16,70 & 4,40 \\
Argentina & 1991 & 7,30 & 1,40 \\
Hungria & 1993 & 5,20 & 3,10 \\
Itália & 1991 & 5,20 & 0,70 \\
Finlândia & 1993 & 4,70 & 2,00 \\
Canadá & 1992 & 2,90 & 1,40 \\
China & 1992 & 2,80 & 1,00 \\
Portugal & 1993 & 2,10 & 1,00 \\
Grécia & 1993 & 1,90 & 0,70 \\
Noruega & 1992 & 1,60 & 0,60 \\
Holanda & 1992 & 1,57 & 0,57 \\
Dinamarca & 1993 & 1,50 & 0,90 \\
Alemanha & 1993 & 1,40 & 1,00 \\
França & 1992 & 1,30 & 0,70 \\
Japão & 1993 & 0,80 & 0,50 \\
\hline Fon & & &
\end{tabular}

Fonte: Organisation Mondiale de la Santé, 1995; Fundação Seade. Sistema de Estatísticas Vitais; Ministério da Saúde, 1998.

população masculina são muito superiores aos da população feminina. Observa-se que a taxa de mortalidade masculina do Estado de São Paulo, já neste período, é uma das mais elevadas, perdendo apenas para a Colômbia, onde é duas vezes maior, seguindo-se, por ordem de importância, Rússia, Brasil, México e EUA. ${ }^{1}$ Entre as mulheres, apesar destes índices serem bem inferiores, ele apresentou um nível bastante elevado, perdendo apenas para a Colômbia, Rússia e EUA (Tabela 1).

Os dados do Ministério da Saúde relativos ao ano de 1997 permitem comparar a situação da mortalidade por homicídios do Estado de São Paulo com as das demais unidades da Federação. Também nesta comparação os índices de mortalidade por homicídios entre os homens são superiores aos das mulheres. Entre os homens, os maiores coeficientes de mortalidade ocorrem nos estados do Rio de Janeiro, Pernambuco e Espírito Santo - todos com índices superiores a 80 óbitos por 100 mil habitantes. Seguem-se em ordem de importância São Paulo, Mato Grosso do Sul, Amapá, Distrito Federal e Roraima, cujos índices ficaram entre 60 e 70 óbitos por 100 mil habitantes. Entre as mulheres, os índices são bem inferiores, ficando abaixo de dez óbitos por 100 mil habitantes em todas as unidades (Gráfico 1).

\section{EVOLUÇÃO DOS HOMICÍDIOS SEGUNDO SEXO E IDADE}

A tendência da mortalidade por homicídios como uma das principais causas de morte da população paulista é cada vez mais preocupante, apresentando um cenário pouco otimista para este final de século. O aumento do número de mortes por homicídios no Estado de São Paulo entre 1998 e 1999 foi de 12,7\%. Os óbitos da população masculina apresentaram um aumento maior que para a população feminina: $13,1 \%$ contra $8,5 \%$. Este aumento se deve à maior participação da população masculina no total de óbitos, que passou de 2.865, em 1980, para aproximadamente 14.600, em 1999. Entre as mulheres, apesar desse volume ser bem inferior, houve um aumento de 333 óbitos para aproximadamente 1.100 óbitos no mesmo período.

A ocorrência dos homicídios é bastante diferenciada nos diversos grupos etários da população. Do total de óbitos por homicídio, o maior percentual é observado na população masculina entre 15 e 39 anos de idade. A participação deste grupo passou de $68,5 \%$ do total de óbitos por homicídios, em 1980, para 77,2\%, em 1999. Entre as mulheres na mesma faixa etária, os percentuais nos dois anos foram inferiores a $10 \%$.

A análise do risco de morte da população paulista constitui um instrumento importante para avaliar o aumento sistemático da mortalidade por homicídios no Estado de São Paulo nos últimos anos, especialmente a partir do início dos anos 80. A taxa de mortalidade por homicídios passou de 12,8 óbitos por 100 mil habitantes em 1980, para 44,2 em 1999, o que se deve, basicamente, ao aumento da mortalidade masculina. Até 1982, as taxas de mortalidade dos homens eram inferiores a 30 óbitos por 100 mil habitantes; a partir desse ano, verifica-se um aumento significativo da mortalidade, com as taxas oscilando entre 40 e 55 óbitos por 100 mil habitantes. Depois de 1993, o aumento é gradativo, atingindo o patamar de 83 óbitos por 100 mil habitantes em 1999. Entre as mulheres, este índices foram bem inferiores. As taxas passaram de três óbitos por 100 mil habitantes em 1980, para seis óbitos por 100 mil em 1999 (Gráfico 2).

Além do aumento gradativo da mortalidade ao longo destes 19 anos de estudo, há uma forte concentração na população jovem e adulta. 


\section{GRÁFICO 1}

Taxas de Mortalidade por Homicídios, segundo Sexo Unidades da Federação - 1997

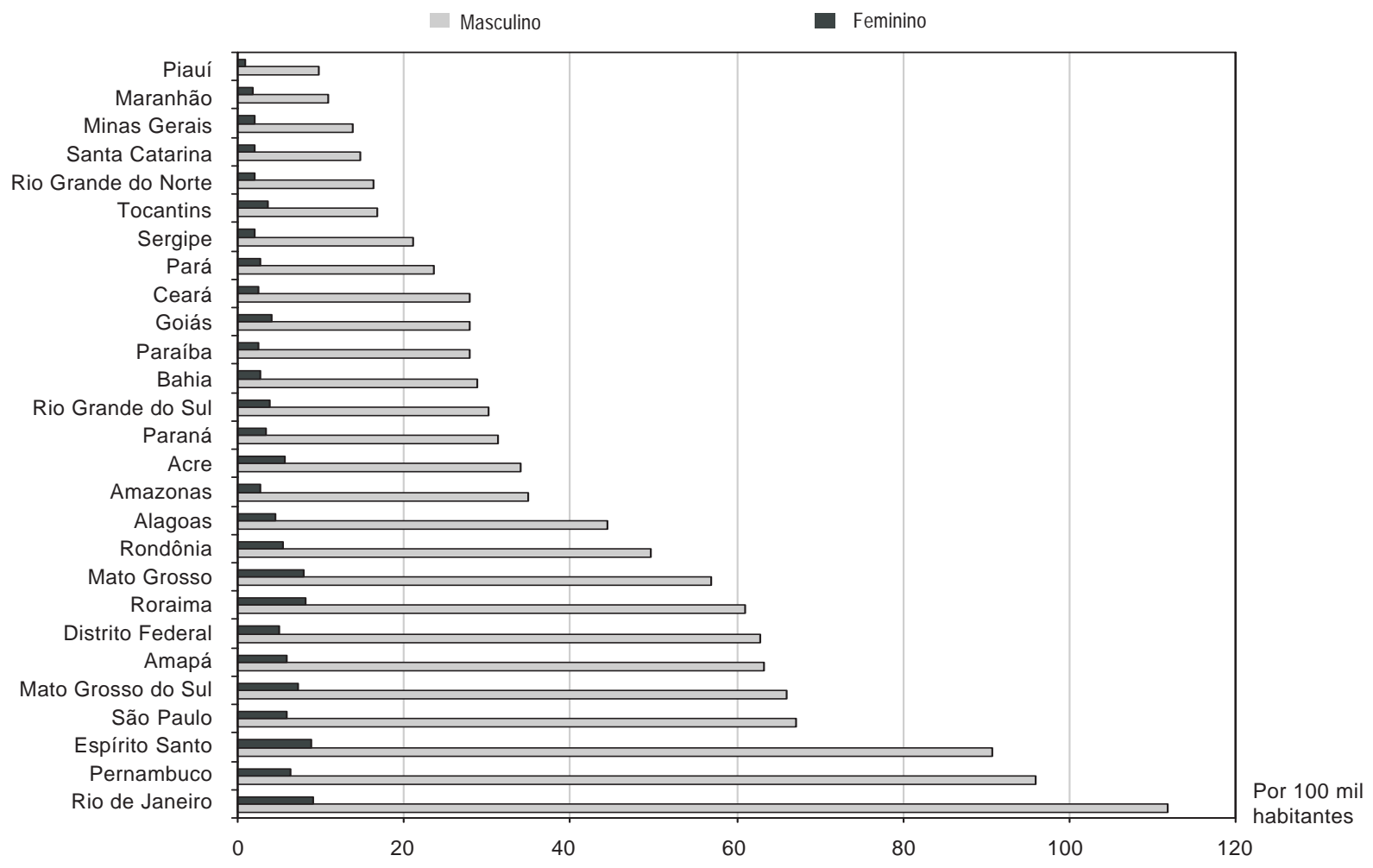

Fonte: Ministério da Saúde, 1998.

GRÁFICO 2

Taxas de Mortalidade por Homicídios, segundo Sexo

Estado de São Paulo - 1980-99

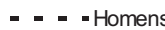

Mulheres

Total

Por 100 mil habitantes

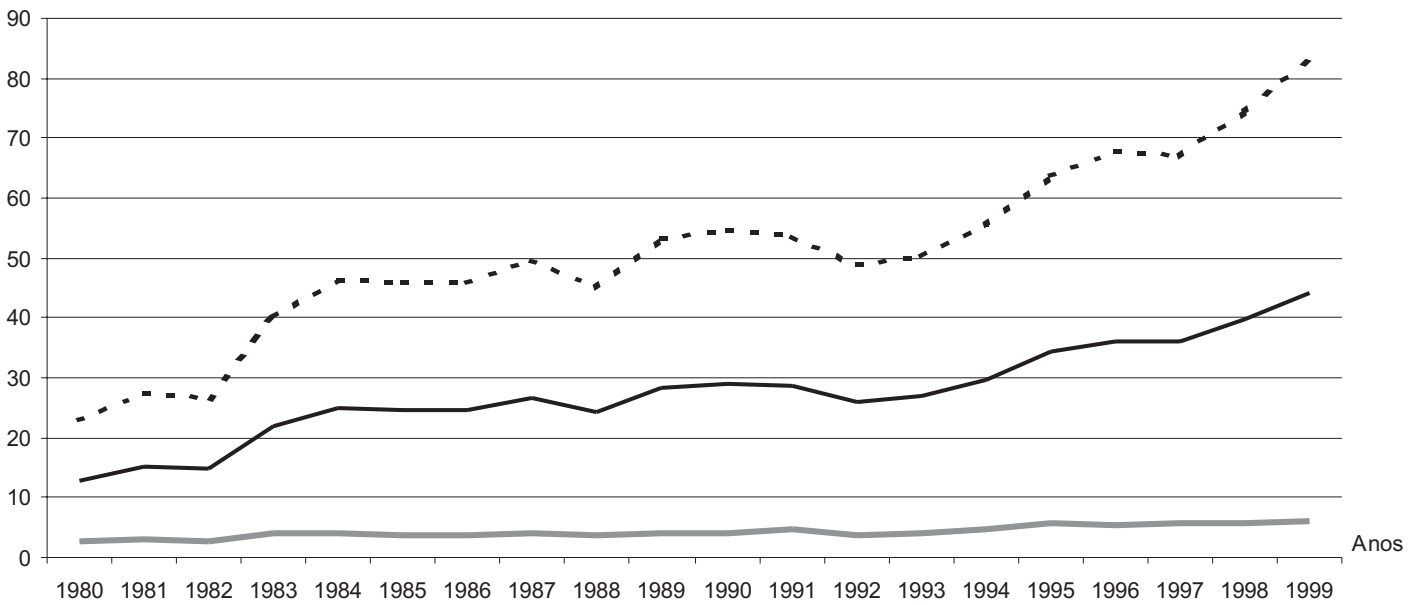

Fonte: Fundação Seade. Sistema de Estatísticas Vitais. 
Nos Gráficos 3 e 4, são apresentadas as curvas de mortalidade por homicídios segundo sexo e idade. Foram selecionados cinco momentos deste período para visualizar o comportamento destas taxas.

Observa-se maior concentração das taxas de mortalidade por homicídio na população entre 15 e 39 anos de idade. Novamente, é possível constatar que as taxas de mortalidade masculina são bem superiores às femininas. Por este motivo, os gráficos foram construídos com escalas distintas para permitir uma melhor avaliação das diferenças entre as taxas de mortalidade.
Constata-se que, para a população masculina, as curvas de mortalidade por homicídios aumentam gradativamente com a idade até atingir o pico no grupo etário de 20 a 24 anos de idade (Gráfico 3). A partir destas idades, começam a diminuir. Entre as mulheres, estas curvas apresentam algumas oscilações, principalmente no início do período (1980 e 1985), quando as taxas eram menores. À medida que os anos passam, estas oscilações desaparecem, e o pico da mortalidade tende a se concentrar nos grupos etários de 25 a 29 anos de idade (Gráfico 4).

\section{GRÁFICO 3}

Taxas de Mortalidade Masculina por Homicídios, segundo Faixa Etária

Estado de São Paulo - 1980-1999

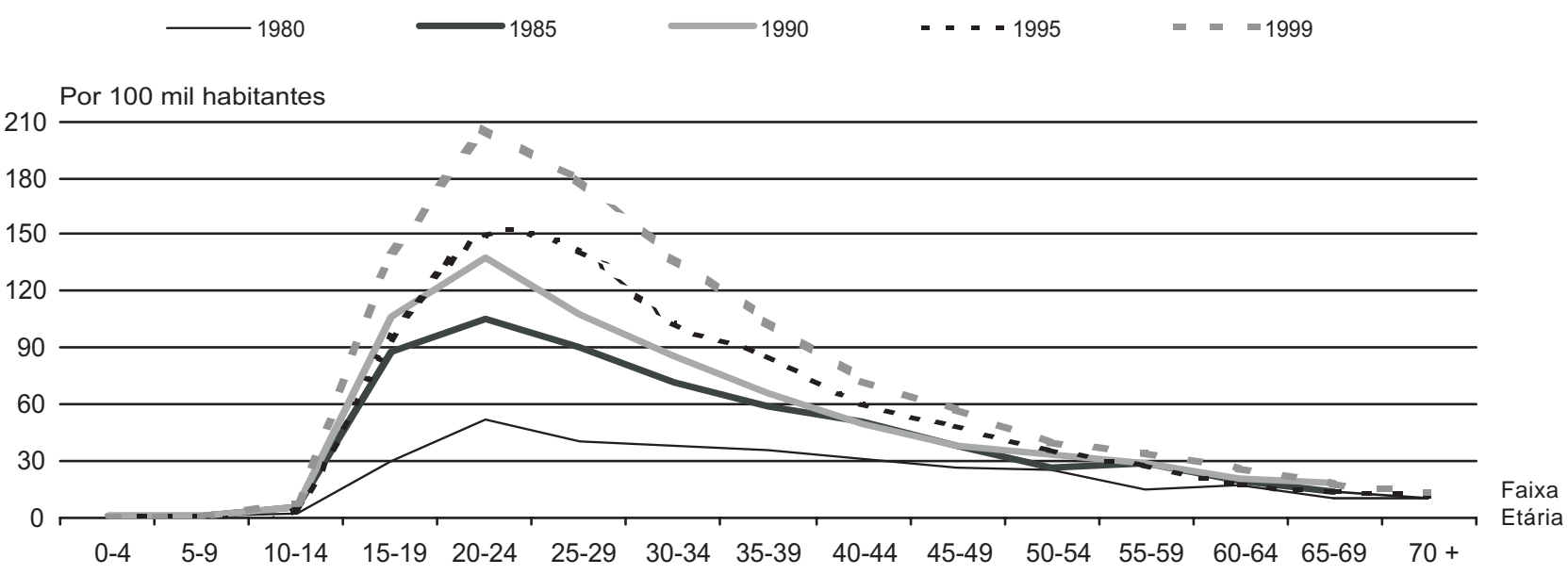

Fonte: Fundação Seade. Sistema de Estatísticas Vitais.

GRÁFICO 4

Taxas de Mortalidade Feminina por Homicídios, segundo Faixa Etária Estado de São Paulo - 1980-1999

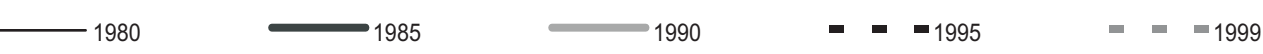

Por 100 mil habitantes

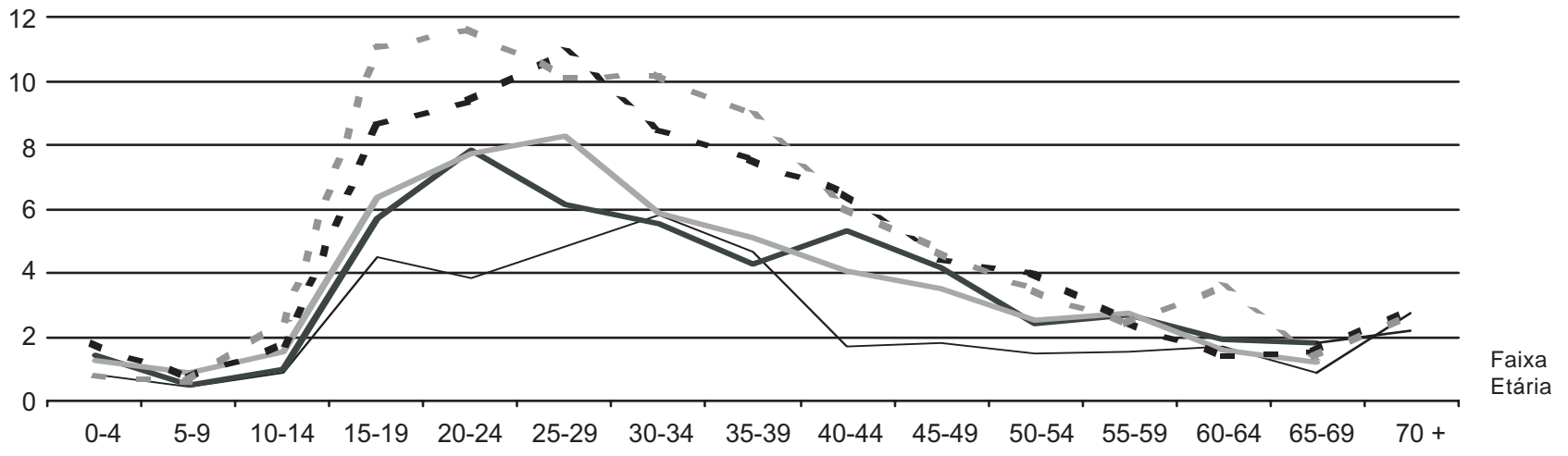

Fonte: Fundação Seade. Sistema de Estatísticas Vitais. 


\section{CARACTERÍSTICAS DAS MORTES POR HOMICÍDIOS}

Um aspecto importante no estudo da mortalidade por homicídios refere-se ao aumento do número de mortes provocadas por armas de fogo. Embora as declarações de óbitos não forneçam informações mais precisas com relação à forma como o homicídio foi praticado, elas possibilitam algumas observações. Em 1980, do total de homicídios do Estado de São Paulo, 20,7\% foram provocados por armas de fogo. No transcorrer deste período, verifica-se um aumento da participação dos óbitos provocados por armas de fogo, que em 1999 representam mais de 50\% do total de mortes por homicídio, aproximadamente $51 \%$ (Gráfico 5).

A Tabela 2 apresenta as taxas de mortalidade dos homicídios provocados por armas de fogo e dos demais homicídios no Estado de São Paulo, entre 1980 e 1999. Verifica-se que as taxas de mortalidade por arma de fogo tiveram um aumento sistemático ao longo de todo o período, passando de 2,7 óbitos por 100 mil habitantes, em 1980, para cerca de 22 óbitos por 100 mil, em 1999 - superando os índices de mortalidade correspondentes aos demais homicídios.

Outra característica importante dos homicídios é a sazonalidade. Na Tabela 3 estão os números médios mensais de homicídios do Estado de São Paulo, em 1999. Verifica-se que não há uma diferença muito marcante entre os meses do ano, mas é possível perceber alguns diferenciais: a maior parcela das mortes por homicídios ocorre nos dois últimos meses do ano, e, a partir de fevereiro, a média de homicídios tende a diminuir até maio.

No Gráfico 6, os óbitos por homicídios ocorridos em 1999 são distribuídos segundo os dias da semana. Verifica-se maior ocorrência de mortes nos domingos e sábados, em que concentram $20 \%$ e $18 \%$, respectivamente, dos homicídios. Nos demais dias, estas proporções são bem

TABELA 2

Taxas de Mortalidade por Homicídios, por Tipo Estado de São Paulo - 1980-1998

Por 100 mil habitantes

\begin{tabular}{lcc}
\hline Anos & $\begin{array}{c}\text { Arma } \\
\text { de Fogo }\end{array}$ & $\begin{array}{c}\text { Demais } \\
\text { Homicídios }\end{array}$ \\
\hline 1980 & 2,65 & 10,16 \\
1981 & 3,43 & 11,71 \\
1982 & 3,26 & 11,48 \\
1983 & 4,89 & 17,03 \\
1984 & 6,60 & 18,32 \\
1985 & 7,03 & 17,72 \\
1986 & 7,26 & 17,30 \\
1987 & 7,95 & 18,69 \\
1988 & 7,98 & 16,34 \\
1989 & 8,85 & 19,59 \\
1990 & 9,19 & 19,88 \\
1991 & 9,50 & 19,30 \\
1992 & 8,65 & 17,43 \\
1993 & 10,87 & 15,96 \\
1994 & 12,24 & 17,56 \\
1995 & 15,32 & 18,91 \\
1996 & 15,66 & 20,39 \\
1997 & 15,42 & 20,68 \\
1998 & 17,86 & 21,84 \\
1999 & 22,48 & 21,70 \\
\hline
\end{tabular}

Fonte: Fundação Seade. Sistema de Estatísticas Vitais.

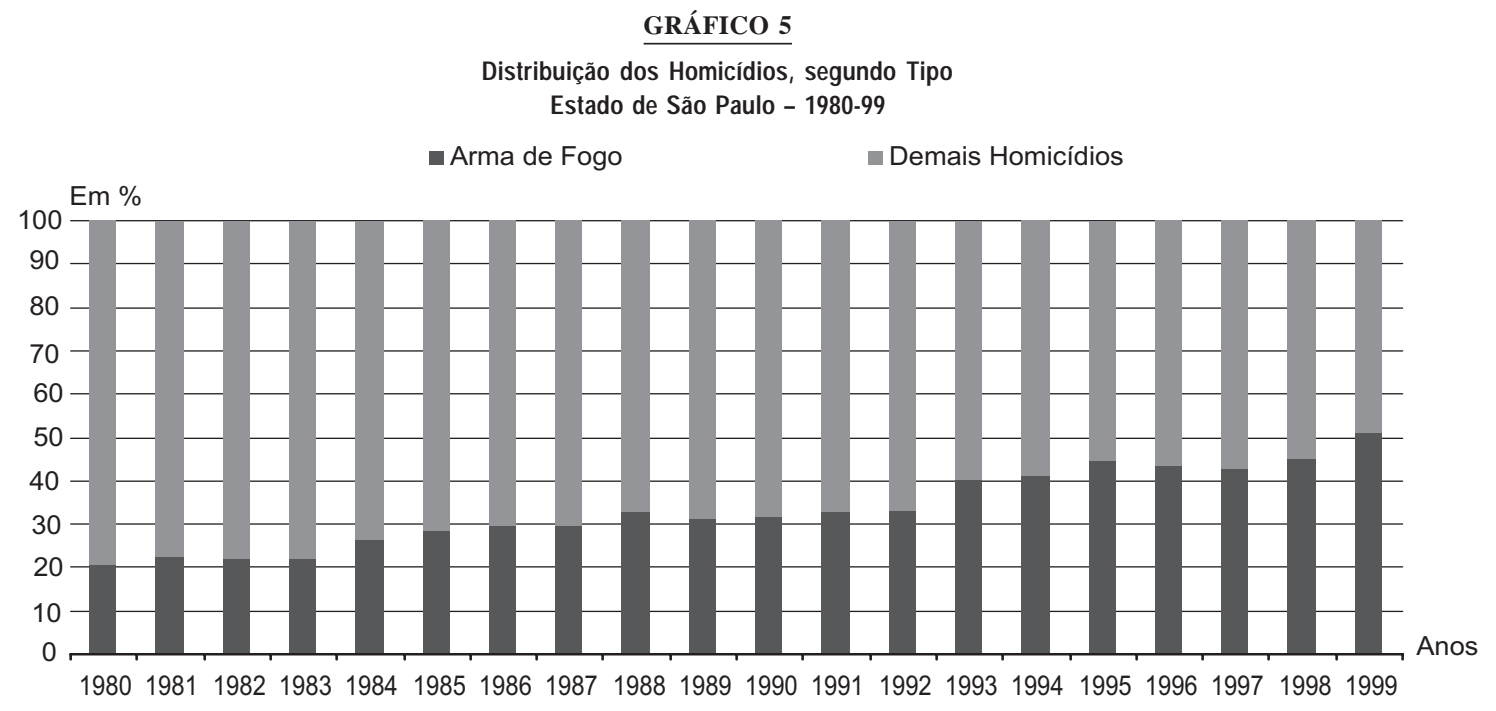

Fonte: Fundação Seade. Sistema de Estatísticas Vitais. 
TABELA 3

Número Médio Mensal dos Óbitos por Homicídios Estado de São Paulo - 1999

\begin{tabular}{lc}
\hline Meses & Média Mensal \\
\hline Janeiro & 42,84 \\
Fevereiro & 44,64 \\
Março & 43,90 \\
Abril & 41,40 \\
Maio & 40,52 \\
Junho & 42,87 \\
Julho & 40,71 \\
Agosto & 43,39 \\
Setembro & 42,13 \\
Outubro & 44,29 \\
Novembro & 47,20 \\
Dezembro & 45,97 \\
\hline
\end{tabular}

Fonte: Fundação Seade. Sistema de Estatísticas Vitais.

menores, em torno de $12 \%$ e $13 \%$, com uma redução até quarta-feira e, a partir deste dia, um aumento gradativo.

Outra variável importante derivada da declaração de óbito, que também permite avaliar o perfil da vítima por homicídio, é o estado civil. O Gráfico 7 mostra que cerca de $68 \%$ dos óbitos por homicídios ocorreram entre solteiros. Entre os casados, esta proporção foi em torno de $18 \%$ e entre os demais estados civis representou aproximadamente $6 \%$. A proporção de ignorados, ou seja, aqueles casos em que não se conhece o estado civil, representou $8,3 \%$ do total de homicídios.

\section{PANORAMA REGIONAL}

As informações referentes às regiões administrativas do Estado de São Paulo mostram que, embora tenha ha- vido aumento da mortalidade por homicídios em praticamente todas as áreas do Estado, isto se deu de forma heterogênea.

Na Tabela 4, apresentam-se as taxas de mortalidade por homicídios para as regiões administrativas do Estado, para os anos de 1979-80, 1989-90 e 1998-99. Observa-se que a Região Metropolitana de São Paulo é a área de maior risco de morte por homicídio. Suas taxas de mortalidade passaram de 15 óbitos por 100 mil habitantes em 1979-80 para 45 em 1989-90 e 63 em 1998-99. Observa-se que nas regiões de Santos, São José dos Campos, Ribeirão Preto e Campinas as taxas de mortalidade praticamente duplicaram entre 1989-90 e 1998-99. Quanto às demais regiões, apenas as de Registro e Barretos apresentaram uma diminuição nos seus índices de mortalidade.

Outra unidade geográfica importante para a análise é a composição por regiões de governo que, por serem menores que as regiões administrativas, permitem um melhor detalhamento da situação da mortalidade por homicídios no Estado de São Paulo. Observa-se na Tabela 5 que as maiores taxas de mortalidade estão concentradas na Região Metropolitana de São Paulo, seguindo-se as de Santos, São José dos Campos, Caraguatatuba e Campinas, cujos índices são superiores à média do Estado, que foi de 44 óbitos por 100 mil habitantes. Também a Região de Governo de Ribeirão Preto apresentou índice elevado, cerca de 31 óbitos por 100 mil habitantes.

Ao se considerarem as taxas de mortalidade por homicídios segundo os municípios do Estado de São Paulo, verifica-se que os maiores índices concentram-se nos municípios da Região Metropolitana de São Paulo e no seu entorno, merecendo destaque Diadema, Embu-Guaçu

GRÁFICO 6

Distribuição dos Óbitos por Homicídios, segundo Dias da Semana

Estado de São Paulo - 1999

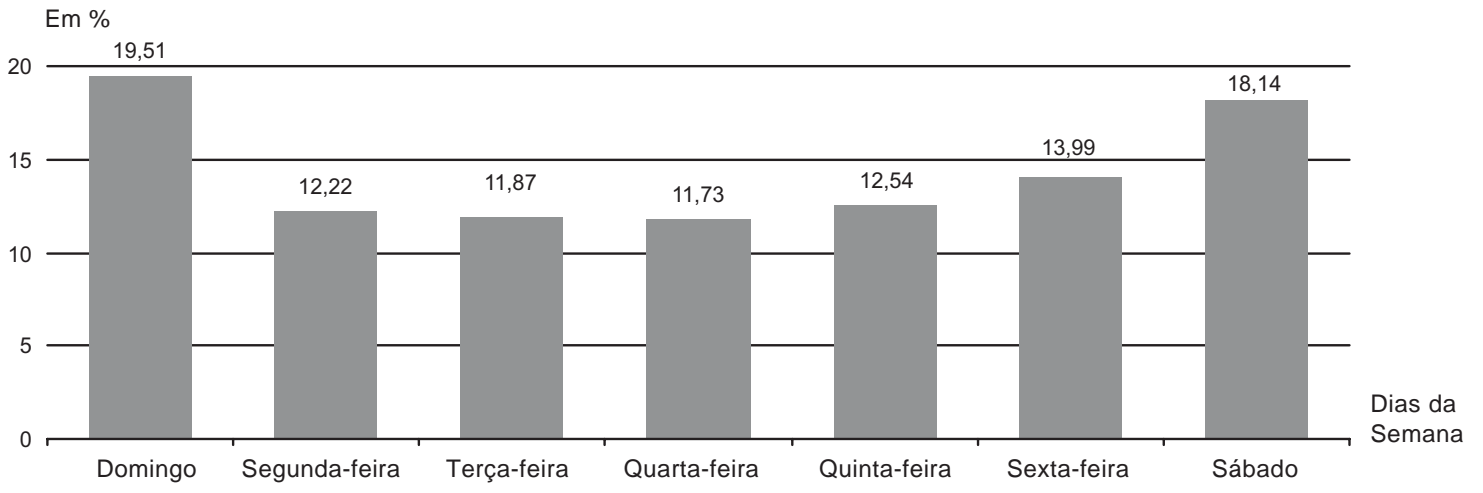

Fonte: Fundação Seade. Sistema de Estatísticas Vitais. 
e Itapecerica da Serra, cujas taxas são superiores a 100 óbitos por homicídios por 100 mil habitantes.

No Mapa 1, encontram-se as taxas dos municípios da Região Metropolitana de São Paulo e, no Mapa 2, as dos distritos da capital. Constata-se que as maiores taxas de mortalidade por homicídio encontram-se na faixa intermediária leste da Região Metropolitana, no extremo leste da capital e a sul e sudeste da região, todos superiores a 60 óbitos por 100 mil habitantes. A parte central dos distritos da capital e o extremo leste da Região Metropolitana de São Paulo são as áreas que apresentam as menores taxas de mortalidade,

\section{GRÁFICO 7}

Distribuição dos Óbitos por Homicídios, segundo Estado Civil Estado de São Paulo - 1999
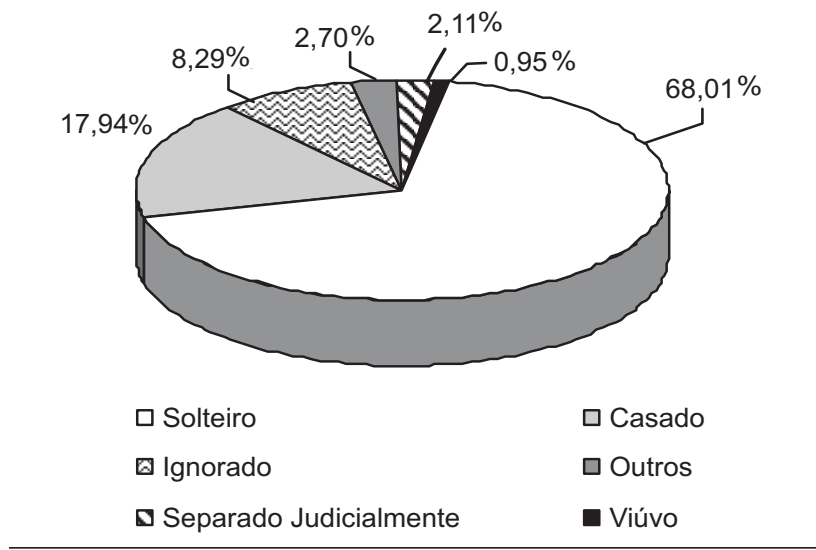

Fonte: Fundação Seade. Sistema de Estatísticas Vitais.

TABELA 4

Taxas de Mortalidade por Homicídios

Regiões Administrativas - 1979-1999

Por 100 mil habitantes

\begin{tabular}{lrrr}
\hline Regiões Administrativas & $1979 / 80$ & $1989 / 90$ & $1998 / 99$ \\
\hline Região Metropolitana de São Paulo & 15,29 & 45,31 & 62,96 \\
Registro & 10,71 & 21,30 & 17,87 \\
Santos & 11,69 & 24,55 & 54,89 \\
São José dos Campos & 11,69 & 18,23 & 33,04 \\
Sorocaba & 6,35 & 13,50 & 16,33 \\
Campinas & 6,28 & 13,04 & 25,64 \\
Ribeirão Preto & 5,91 & 11,61 & 28,33 \\
Bauru & 3,67 & 7,65 & 11,10 \\
São José do Rio Preto & 4,34 & 6,55 & 7,98 \\
Araçatuba & 8,01 & 9,41 & 14,75 \\
Presidente Prudente & 6,11 & 9,35 & 11,68 \\
Marília & 5,30 & 8,94 & 12,53 \\
Central & 6,57 & 9,46 & 12,84 \\
Barretos & 5,63 & 9,02 & 5,94 \\
Franca & 4,56 & 6,16 & 6,98 \\
\hline
\end{tabular}

Fonte: Fundação Seade. Sistema de Estatísticas Vitais. inferiores a 30 óbitos por 100 mil habitantes. Observa-se que existe uma grande heterogeneidade entre as taxas de mortalidade dessas áreas. Para se ter uma idéia desta grandeza, o risco de um residente do Município de Diadema morrer por

TABELA 5

Taxas de Mortalidade por Homicídios Regiões de Governo do Estado de São Paulo - 1999

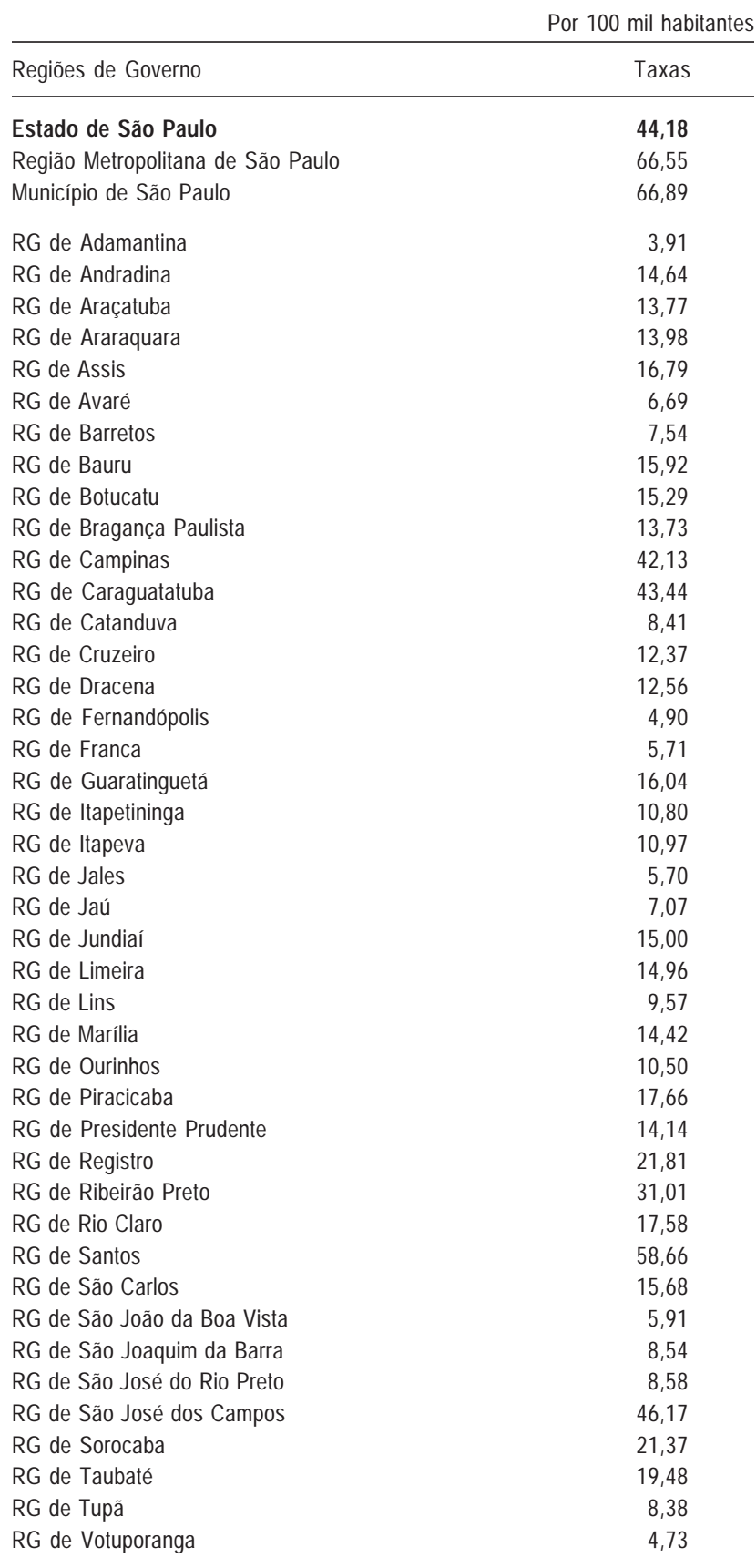

Fonte: Fundação Seade. Sistema de Estatisticas Vitais. 

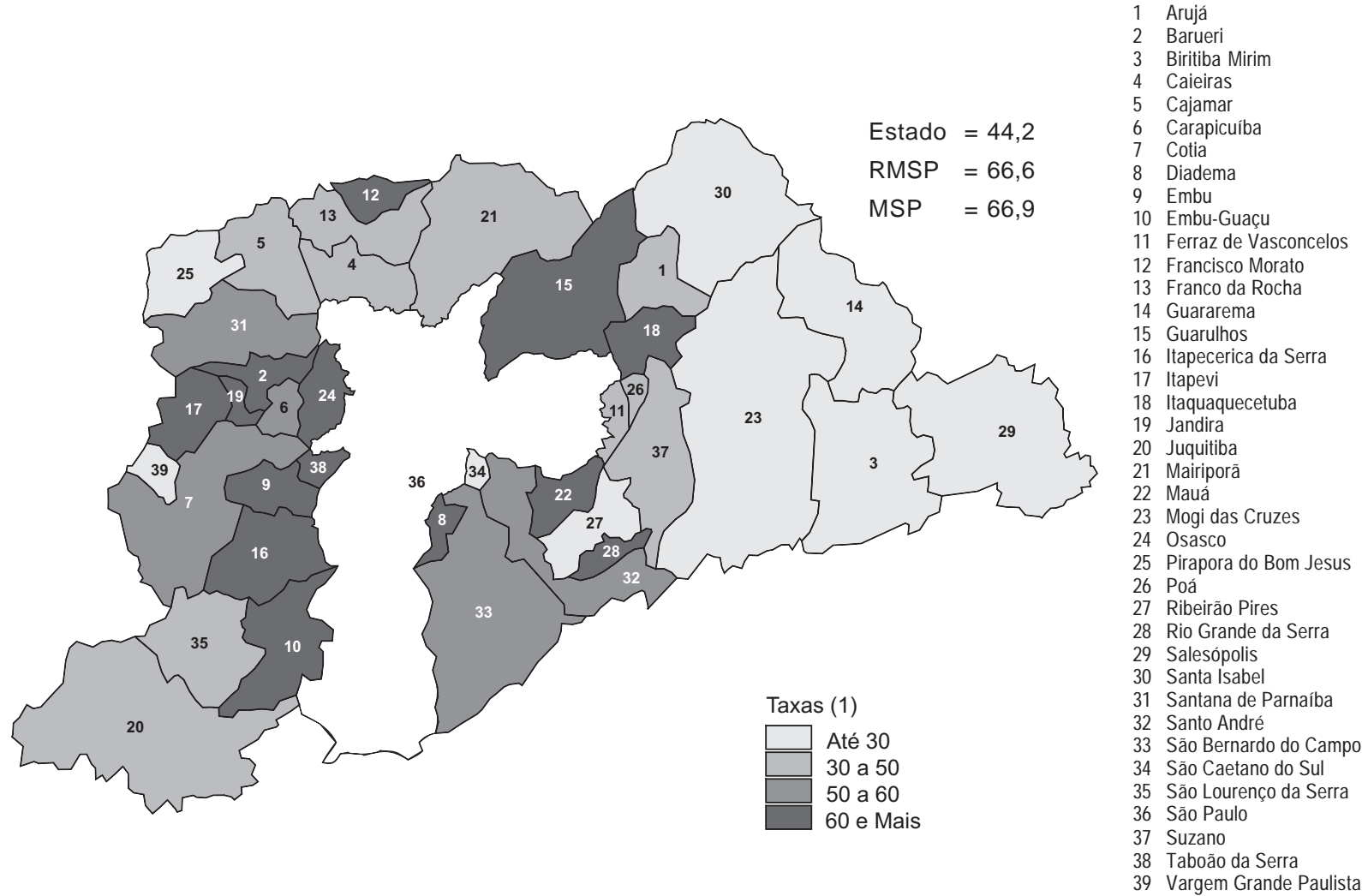

Fonte: Fundação Seade. Sistema de Estatísticas Vitais.

(1) Por 100 mil habitantes.

homicídio é 35 vezes maior que um residente do distrito de Moema.

\section{CONSIDERAÇÕES FINAIS}

Os resultados obtidos a partir da análise da mortalidade por homicídios, no Estado de São Paulo, ratificam a elevada ocorrência destes óbitos. A análise mostrou também que o risco de um cidadão paulista morrer vítima de violência é diferencial por uma série de atribuições sociais e demográficas, tais como sexo, idade, estado civil, local de residência, entre outras.

Uma outra questão importante, observada neste trabalho, é a crescente magnitude que estas mortes vêm assumindo ao longo destes 19 anos, em grande parte devido ao aumento do número de mortes por armas de fogo. Merece destaque, também, o intenso crescimento nos úl- timos oito anos da mortalidade por homicídios em algumas regiões do interior do Estado de São Paulo, revelando uma situação cada vez mais preocupante.

O mapeamento das mortes por homicídios e a análise das características demográficas e sociais das vítimas são instrumentos relevantes para o monitoramento da conseqüente mortalidade. Estas informações podem contribuir para o planejamento de ações na área de segurança, no sentido de procurar minimizar esta questão que preocupa a todos.

\section{NOTAS}

E-mail do autor: pmaia@ seade.gov.br

1. Esta comparação apresenta algumas limitações, uma vez que poucos países classificados como subdesenvolvidos ou em desenvolvimento dispõem de informações relativas às causas de morte. 
MAPA 2

Taxas de Mortalidade por Homicídios, segundo Distritos da Capital Município de São Paulo - 1999

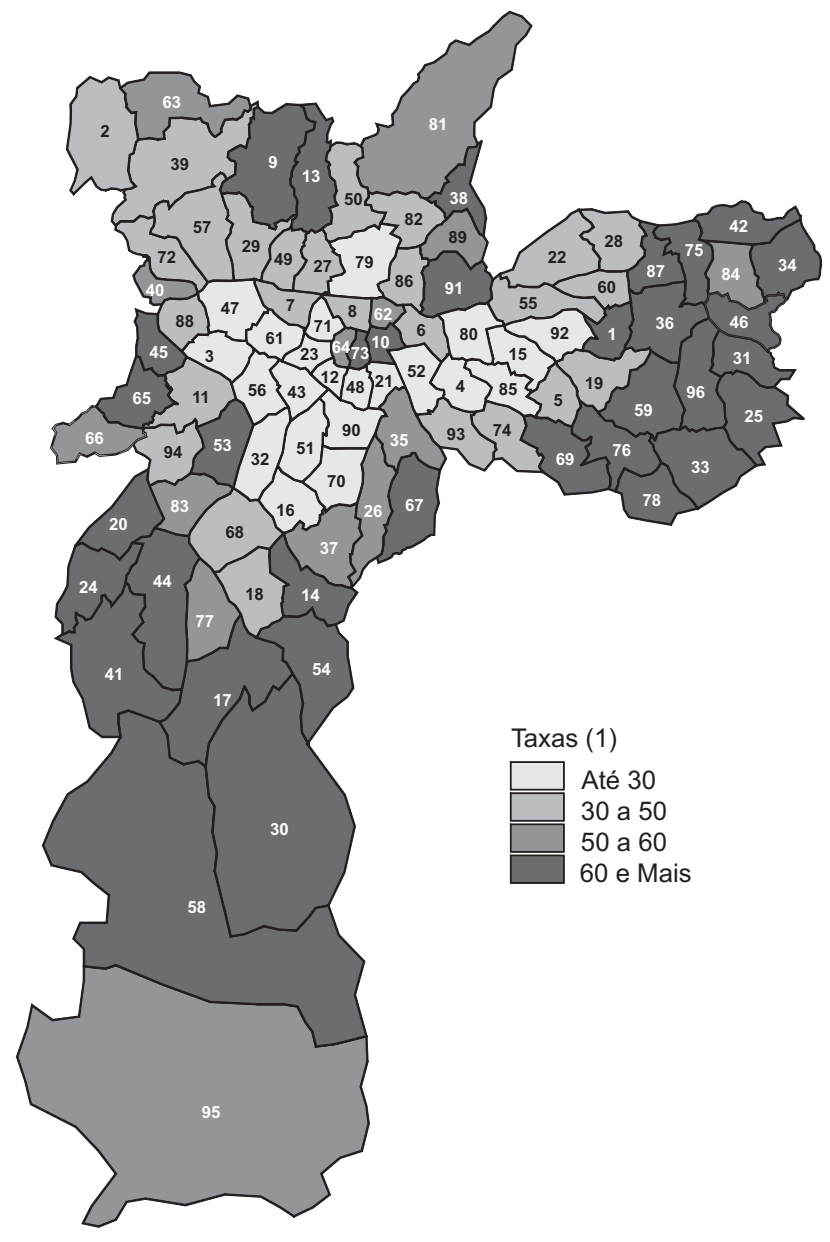

Distritos da Capital

1 Artur Alvim

2 Anhangüera

3 Alto de Pinheiros

Água Rasa

Aricanduva

6 Belém

7 Barra Funda

8 Bom Retiro

9 Brasilândia

10 Brás

11 Butantã

12 Bela Vista

13 Cachoeirinha

14 Cidade Ademar

15 Carrão

16 Campo Belo

17 Cidade Dutra

18 Campo Grande

19 Cidade Líder

20 Campo Limpo

21 Cambuci

22 Cangaíba

23 Consolação

24 Capão Redondo

25 Cidade Tiradentes

26 Cursino

27 Casa Verde

28 Ermelino Matarazzo

29 Freguesia do O

30 Grajaú

31 Guaianases

32 Itaim Bibi
33 Iguatemi

34 Itaim Paulista

35 Ipiranga

36 Itaquera

37 Jabaquara

38 Jaçanã

39 Jaraguá

40 Jaguara

41 Jardim Ângela

42 Jardim Helena

43 Jardim Paulista

44 Jardim São Luís

45 Jaguaré

46 Lajeado

47 Lapa

48 Liberdade

49 Limão

50 Mandaqui

51 Moema

52 Mooca

53 Morumbi

54 Pedreira

55 Penha

56 Pinheiros

57 Pirituba

58 Parelheiros

59 Parque do Carmo

60 Ponte Rasa

61 Perdizes

62 Pari

63 Perus

64 República
65 Rio Pequeno

66 Raposo Tavares

67 Sacomã

68 Santo Amaro

69 Sapopemba

70 Saúde

71 Santa Cecília

72 São Domingos

73 Sé

74 São Lucas

75 São Miguel

76 São Mateus

77 Socorro

78 São Rafael

79 Santana

80 Tatuapé

81 Tremembé

82 Tucuruvi

83 Vila Andrade

84 Vila Curuçá

85 Vila Formosa

86 Vila Guilherme

87 Vila Jacui

88 Vila Leopoldina

89 Vila Medeiros

90 Vila Mariana

91 Vila Maria

92 Vila Matilde

93 Vila Prudente

94 Vila Sônia

95 Marsilac

96 José Bonifácio

Fonte: Fundação Seade. Sistema de Estatísticas Vitais.

(1) Por 100 mil habitantes.

\section{REFERÊNCIAS BIBLIOGRÁFICAS}

BRASIL. Ministério da Saúde. Rede internacional de informações para saúde. IDB 98 Brasil: indicadores de dados básicos para a saúde. Brasília, 1998. (Internet: www.datasus.gov.br)

CAMARGO, A.B.M. et alii. "Evolução da mortalidade por acidentes e violências em áreas metropolitanas". In: MONTEIRO, C.A. (org.). Velhos e novos males na saúde no Brasil. A evolução do país e de suas doenças. São Paulo, Hucitec, 1995.

FERREIRA, C.E.C. e CASTIÑEIRA, L. "O rápido aumento da mortalidade dos jovens adultos em São Paulo: uma trágica tendência”. São Paulo em Perspectiva. São Paulo, Fundação Seade, v.10, n.2, abr./jun. 1996, p.35-41.

FUNDAÇÃO SEADE. Sistema de Estatísticas Vitais.

MELLO JORGE, M.H.P. Investigação sobre mortalidade por acidentes e violência na infância. Tese de livre docência. São Paulo, Faculdade de Saúde Pública, Universidade de São Paulo, 1988.
MINAYO, M.C. de S. "A violência social sob a perspectiva da saúde pública". $\mathrm{Ca}$ dernos de Saúde Pública. Rio de Janeiro, n.10, 1994, p.7-18 (suplemento 1).

ORGANISATION MONDIALE DE LA SANTÉ. Annuaire de Statistiques Sanitaires Mondeales. Genève, 1995.

SAAD, P.M. et alii. "Vítimas potenciais da violência". Vinte anos no ano 2000. estudos sociodemográficos sobre a juventude paulista. São Paulo, Fundação Seade, 1998, p.58-73.

SOUZA, E.R. "Homicídios no Brasil: o grande vilão da saúde pública na década de 80". Cadernos de Saúde Pública. Rio de Janeiro, n.10, 1994, p.45-60 (suplemento 1).

SOUZA, E.R. e ASSIS, S.G. Violência e mortalidade na América Latina: um estudo das causas externas de 1968 a 1986. Rio de Janeiro, Centro LatinoAmericano de Estudos sobre a Violência e Saúde, Escola Nacional de Saúde Pública, Fundação Oswaldo Cruz, 1989, mimeo.

SZWARCWALD, C.L. "Tendências da mortalidade por causas externas no Rio de Janeiro, 1976-1985". III Jornada Científica da Fiocruz. Anais... Rio de Janeiro, Fundação Oswaldo Cruz, 1989, p.37-42. 